\title{
Editorials
}

\section{Preventive Use of Noninvasive Ventilation After Planned Extubation}

Despite a thorough weaning assessment, including a spontaneous breathing trial (SBT), liberation from mechanical ventilation via endotracheal extubation is associated with re-intubation rates of up to $24 \% .{ }^{1}$ Re-intubation, in turn, is associated with an increased risk of mortality, intensive care unit (ICU) stay, need for transfer to longterm care facility, ${ }^{2}$ and nosocomial pneumonia. ${ }^{3}$ Avoiding re-intubation is therefore an important goal in weaning mechanically ventilated patients. As part of achieving this goal and improving weaning outcome in general, noninvasive ventilation (NIV) has been increasingly studied and utilized during the last 15 years. This increasingly frequent use is reflected in a recent European survey suggesting that NIV is being utilized by clinicians almost as frequently for weaning as it is for initial respiratory failure due to cardiogenic pulmonary edema. ${ }^{4}$

The use of NIV during weaning from mechanical ventilation can be divided into 3 types. First, NIV can be used as an adjunct to early separation from invasive mechanical ventilation in patients who have achieved a minimal clinical and respiratory stabilization but who fail an SBT and need only transient low/intermittent ventilatory support. This type of NIV use is supported by several studies that, compared with usual invasive ventilation weaning mostly in COPD patients, have shown that NIV resulted in shorter duration of mechanical ventilation and lower incidence of complications, with no difference in re-intubation rates. ${ }^{5-8}$ Second, NIV can be used as rescue therapy for patients who develop respiratory distress or failure soon after extubation. Two randomized controlled studies testing this type of NIV application versus usual care in patients with respiratory failure of multiple etiologies showed no difference in re-intubation rates, ${ }^{9,10}$ and one of them suggested higher ICU mortality in the NIV group, possibly from delaying the necessary re-intubation. ${ }^{9}$ These findings led to the idea that, by the time post-extubation respiratory failure has developed, it may be too late for the patient to be "rescued" from re-intubation using NIV. Therefore, the third type of NIV use studied in weaning has been its early or preventive use right after planned extubation following tolerance of an SBT. This is applied with the intention of preventing post-extubation respiratory failure, which some patients might develop, and by extension re-intubation, with its associated risks. Several randomized controlled trials have evaluated this type of NIV use (preventive NIV), the focus of this editorial.
Nava et al $^{11}$ randomized 97 patients with at least one risk factor for post-extubation respiratory failure (prior weaning trial failure, congestive heart failure, $\mathrm{P}_{\mathrm{aCO}_{2}}$ $\geq 45 \mathrm{~mm} \mathrm{Hg}$ after extubation, $\geq 1$ comorbidity, weak cough, stridor) to 48 hours of preventive NIV versus usual care (without NIV rescue) and showed a significant decrease in re-intubation rate (16\% absolute difference) with NIV, but no direct effect on ICU or hospital stay and mortality. Ferrer et al ${ }^{12}$ randomized 162 patients with at least one of the following different risk factors (age $>65$, congestive heart failure as cause of respiratory failure, APACHE II $>12$ ) to 24 hours of preventive NIV (with additional NIV rescue) versus usual care with NIV rescue, showing a decrease of post-extubation respiratory failure with preventive NIV, but no significant difference in reintubation rate or length of stay. They also noted a lower ICU mortality in the preventive NIV group, but no difference in hospital or 90 day mortality. This same Spanish group $^{13}$ subsequently performed a similar trial, but now selecting 106 patients who had chronic lung disease $(>70 \%$ with (OPD) and $\mathrm{P}_{\mathrm{aCO}_{2}} \geq 45 \mathrm{~mm} \mathrm{Hg}$ at the end of an otherwise successful SBT. Similar to their first study, they showed a decrease in the proportion of patients meeting criteria for post-extubation respiratory failure with preventive NIV, but no significant difference in re-intubation rate. ICU and hospital length of stay and mortality were no different, but an intriguing 90 day mortality advantage for the preventive NIV group was noted.

\section{See the Original Study on Page 204}

In this issue of Respiratory CARe, $\mathrm{Su}$ et $\mathrm{al}^{14}$ report a large prospective randomized trial performed in 3 ICUs in Taiwan, aiming to evaluate whether the preventive use of NIV after planned extubation would reduce re-intubation rate. Different from prior studies, this study did not select patients according to risk of post-extubation respiratory failure. The study patients belong to a mixed ICU population with multiple causes of respiratory failure. After being ventilated for at least 48 hours and passing a basic weaning evaluation and an SBT, 406 patients were randomized to preventive NIV for up to 72 hours versus usual care with NIV rescue. The authors found no difference in the rate of post-extubation respiratory failure and rate of re-intubation. In view of the prior studies addressing the 
preventive use of NIV after planned extubation, these results are not surprising but add to the evidence from those to draw some comments on their overall findings.

The selection of the appropriate patients who may benefit from preventive NIV is a key issue. This selection should include a high risk of post-extubation respiratory failure, a condition likely to respond to low level ventilatory support, and the minimization of factors that impair the effectiveness of NIV (inadequate airway clearance and mental status). The unselective approach of the Su et al study, ${ }^{14}$ at least as far as the first 2 elements, seems not beneficial. The criteria for selection in the other studies, ${ }^{11-13}$ although with few in common, were quite different from each other. Further definition of this patient selection is needed before clear clinical recommendations can be made. In the meantime, it is reasonable to suspect that the conditions where NIV can prevent the original intubation may be the same where NIV can prevent the potential re-intubation.

The end points used in the trials to measure the benefit of preventive NIV merit comment. Only one study showed a decrease in re-intubation rate. ${ }^{11}$ The other 2 positive studies $^{12,13}$ showed a decrease in post-extubation respiratory failure but not in re-intubation rate. Preventive NIV would be very beneficial if it prevented re-intubation, because there are important complications associated with the need for re-intubation. Post-extubation respiratory failure that does not proceed to re-intubation, although important, has not yet been associated with the risks of reintubation. If re-intubation rate is not different, is it worth placing every extubated patient (of a selected population) on NIV when we can achieve the same re-intubation rate using NIV rescue in $23-38 \%$ of them? ? $^{12,13}$

Three possibilities can be entertained to explain the discrepant results between the end points post-extubation respiratory failure and re-intubation: that rescue NIV in the control group prevents re-intubations (an assumption that has not been proven, see next paragraph); that some patients who develop post-extubation respiratory failure stabilize on their own not to need re-intubation regardless of NIV; and/or that the studies were not powered to detect a significant difference in re-intubation rate (given a control re-intubation rate of about 20\%).12,13 Looking at a downstream and more important end point beyond re-intubation, the impact of preventive NIV on mortality in these studies has been neutral, inconsistent, or difficult to explain. ${ }^{11-14}$ A recent meta-analysis ${ }^{15}$ of the 3 European studies $^{11-13}$ and a prior Chinese randomized trial ${ }^{16}$ reported a pooled decrease in re-intubation rate and ICU mortality, but no difference in hospital mortality. It is reasonable however, to be skeptical of these results, given the heterogeneity among the studies.
The treatment of the control groups to which preventive NIV was compared also deserves consideration. The only study that showed decrease in re-intubation rate ${ }^{11} \mathrm{com}-$ pared preventive NIV versus usual care without rescue NIV. It can be speculated that not including rescue NIV was the reason this study found a difference. The other 3 studies $^{12-14}$ compared preventive NIV versus usual care that included rescue NIV. This latter comparison is therefore preventive NIV versus rescue NIV (the third vs the second type of NIV use in weaning). It is interesting that "usual care" in these latter studies included a therapy (rescue NIV) that has not been proven beneficial, or has even been suggested to be detrimental, by randomized studies. ${ }^{9}, 10$ Only a study of a prospective cohort with acute exacerbation of COPD compared with historical matched controls offered direct evidence that the use of rescue NIV could decrease re-intubations ${ }^{17}$ when compared to plain usual care. It is likely that this study, evidence from the use of NIV in the setting of initial respiratory failure and early discontinuation of invasive ventilation in selected populations, and clinical experience have been enough to incorporate rescue NIV into "usual care."

The latest published guidelines on NIV 15 recommend the use of preventive NIV after planned extubation in patients "considered to be at high risk for recurrent respiratory failure, but only in centers that have expertise" in NIV. Its use in patients at low risk for post-extubation respiratory failure is not recommended. The current study by $\mathrm{Su}$ et $\mathrm{al}^{14}$ now supports this latter recommendation.

From the considerations on the current evidence described, future studies on preventive NIV should consider refining patient selection, a sample size to obtain statistical power to address re-intubation rate as an end point, and a 3 arm comparison between preventive NIV versus rescue NIV versus usual care without rescue NIV. The latter arm would provide rigorous scientific evidence for the benefit of rescue NIV, but may find resistance due to the experience and comfort of clinicians with "usual care." Finally, for well selected subgroups of patients, like acute exacerbation of chronic hypercapnic respiratory failure, the different types of NIV use in weaning are likely to blend toward early liberation from invasive ventilation (to expedite weaning) with additional rescue NIV support (to minimize re-intubation). ${ }^{8}$ Preventive NIV may still have a role for other selected subgroups of patients at risk and for some of us too hesitant to extubate a patient who cannot tolerate an SBT.

Juan B Figueroa-Casas MD Division of Pulmonary and Critical Care Medicine Paul L Foster School of Medicine Texas Tech University Health Science Center El Paso, Texas 


\section{Preventive Use of Noninvasive Ventilation After Planned Extubation}

\section{REFERENCES}

1. Cohen J, Shapiro M, Grozovski E, Lev S, Fisher H, Singer P. Extubation outcome following a spontaneous breathing trial with automatic tube compensation versus continuous positive airway pressure. Crit Care Med 2006;34(3):682-686.

2. Epstein S, Ciubotaru R, Wong J. Effect of failed extubation on the outcome of mechanical ventilation. Chest 1997;112(1):186-192.

3. Torres A, Gatell J, Aznar E, el-Ebiary M, Puig de la Bellacasa J, Gonzalez J, et al. Re-intubation increases the risk of nosocomial pneumonia in patients needing mechanical ventilation. Am J Respir Crit Care Med 1995;152(1):137-141.

4. Crimi C, Noto A, Princi P, Esquinas A, Nava S. A European survey of noninvasive ventilation practices. Eur Respir J 2010;36(2):362369.

5. Nava S, Ambrosino N, Clini E, Prato M, Orlando G, Vitacca M, et al. Noninvasive mechanical ventilation in the weaning of patients with respiratory failure due to chronic obstructive pulmonary disease. Ann Intern Med 1998;128(9):721-728.

6. Ferrer M, Esquinas A, Arancibia F, Bauer TT, Gonzalez G, Carrillo A, et al. Noninvasive ventilation during persistent weaning failure: a randomized controlled trial. Am J Respir Crit Care Med 2003;168(1): 70-76.

7. Girault C, Daudenthun I, Chevron V, Tamion F, Leroy J, Bonmarchand G. Noninvasive ventilation as a systematic extubation and weaning technique in acute-on-chronic respiratory failure: a prospective, randomized controlled study. Am J Respir Crit Care Med 1999; 160(1):86-92

8. Girault C, Bubenheim M, Abroug F, Diehl JL, Elatrous S, Beuret P, et al. Noninvasive ventilation and weaning in patients with chronic

The author has disclosed no conflicts of interest.

Correspondence: Juan B Figueroa-Casas MD, Division of Pulmonary and Critical Care Medicine, Paul L Foster School of Medicine, Texas Tech University Health Science Center, 4800 Alberta Avenue, El Paso TX 79905. E-mail: Juan.Figueroa@ttuhsc.edu.

DOI: $10.4187 /$ respcare. 01657 hypercapnic respiratory failure: a randomized multicenter trial. Am J Respir Crit Care Med 2011;184(6):672-679.

9. Esteban A, Frutos-Vivar F, Ferguson ND, Arabi Y, Apezteguia C, Gonzalez M, et al. Noninvasive positive-pressure ventilation for respiratory failure after extubation. N Engl J Med 2004;350(24):24522460.

10. Keenan SP, Powers C, McCormack DG, Block G. Noninvasive positive-pressure ventilation for postextubation respiratory distress. JAMA 2002;287(24):3238-3244.

11. Nava S, Gregoretti C, Fanfulla F, Squadrone E, Grassi M, Carlucci A, et al. Noninvasive ventilation to prevent respiratory failure after extubation in high-risk patients. Crit Care Med 2005;33(11):24652470.

12. Ferrer M, Valencia M, Nicolas JM, Bernadich O, Badia JR, Torres A. Early noninvasive ventilation averts extubation failure in patients at risk: a randomized trial. Am J Respir Crit Care Med 2006;173(2): 164-170.

13. Ferrer M, Sellarés J, Valencia M, Carrillo A, Gonzalez G, Badia JR, et al. Non-invasive ventilation after extubation in hypercapnic patients with chronic respiratory disorders: randomised controlled trial. Lancet 2009;374(9695):1082-1088.

14. Su C-L, Chiang L-L, Yang S-H, Lin HY, Cheng K-C, Huang Y-C, Wu C-P. Preventive use of noninvasive ventilation after extubation: a prospective, multicenter randomized controlled trial. Respir Care 2011;57(2):204-210.

15. Keenan SP, Sinuff T, Burns KEA, Muscedere J, Kutsogiannis J, Mehta S, et al. Clinical practice guidelines for the use of noninvasive positive-pressure ventilation and noninvasive continuous positive airway pressure in the acute care setting. CMAJ 2011;183(3):E195E214.

16. Luo H, Cheng P, Zhou R. [Sequential BiPAP following invasive mechanical ventilation in COPD patients with hypercapnic respiratory failure]. Bulletin of Hunan Medical University 2001;26(6):563565. Article in Mandarin.

17. Hilbert G, Gruson D, Portel L, Gbikpi-Benissan G, Cardinaud J. Noninvasive pressure support ventilation in COPD patients with postextubation hypercapnic respiratory insufficiency. Eur Respir J 1998; 11(6):1349-1353. 